\title{
ADUBAÇÃO NITROGENADA EM COBERTURA: FATOR DETERMINANTE PARA ELEVADAS PRODUTIVIDADES DE FEIJÃO COMUM
}

Ivanildo Guilherme Henrique $^{1 *}$, Indianara Cazuza do Nascimento ${ }^{2}$, Ítallo Diego de Souza ${ }^{2}$, Gabriel Rafael de Andrade ${ }^{2}$, Paulo Henrique Alves Morais ${ }^{1}$ Dayane Barbosa Pereira ${ }^{3}$, Luiz Cobiniano de Melo Filho ${ }^{4}$

\footnotetext{
${ }^{1}$ Mestrando em Agronomia, Instituto de Ciências Agrárias e Ambientais - ICAA, Universidade Federal de Mato Grosso - UFMT, Sinop, MT. *E-mail do autor correspondente: ivanildo.guilhermee@gmail.com

${ }^{2}$ Graduando, Instituto Federal de Educação, Ciência e Tecnologia de Rondônia, IFRO, Colorado do Oeste, RO

${ }^{3}$ Engenheira Agrônoma, Agrocat Distribuidora Insumos Agrícolas LTDA, AGROCAT, Vilhena, RO

${ }^{4}$ Docente, Instituto Federal de Educação, Ciência e Tecnologia de Rondônia, IFRO, Colorado do Oeste, RO
}

RESUMO: Considerando a grande exigência do feijoeiro em nutrientes, destaca-se a alta demanda da cultura por nitrogênio $(\mathrm{N})$. Dessa maneira, objetivou-se avaliar se a inoculação de sementes, com Azospirillum brasilense e adubação nitrogenada e molíbdica, em cobertura, influenciam os caracteres agronômicos e o rendimento produtivo do feijão comum. Para tanto, empregou-se o delineamento experimental de blocos casualizados, em esquema fatorial $2 \times 2 \times 2$, com quatro repetições. Avaliou-se a inoculação de sementes (sem inoculação e com inoculação de A. brasilense), aplicação foliar de molibdênio (sem aplicação e com aplicação de $126 \mathrm{~g} \mathrm{ha}^{-1}$ ) e fornecimento de nitrogênio em cobertura (sem aplicação e com aplicação de $30 \mathrm{~kg} \mathrm{ha}^{-1}$ ). Os ensaios foram conduzidos no município de Colorado do Oeste, Rondônia, nos anos de 2017 e 2018, adotando sistema de semeadura direta. Utilizou-se a cultivar BRS Estilo e para inoculação das sementes as estirpes AbV5 e AbV6 com 2x10 ${ }^{8} \mathrm{Ufc} \mathrm{g}^{-1}$. O molibdênio foliar foi aplicado, em dose única, aos 19 dias após a emergência das plântulas e o nitrogênio, fornecido por ocasião da fase de desenvolvimento reprodutivo R5, utilizando como fonte a ureia, aplicada manualmente na linha de plantio. A inoculação das sementes de feijão, com $A$. brasilense, resulta em aumento da produtividade quando associada a adubação nitrogenada em cobertura. A adubação nitrogenada em cobertura é determinante no aumento de produtividade do feijão comum.

Palavras-chave: Nodulação. Rizóbio. Fixação biológica. Inoculação. Molibdênio.

\section{COVERED NITROGEN FERTILIZATION: DETERMINANT FACTOR FOR HIGH COMMON BEAN PRODUCTIVITIES}

\begin{abstract}
Considering the great demand of beans for nutrients, the high demand of the crop for nitrogen $(\mathrm{N})$ stands out. Thus, the objective was to evaluate whether the inoculation of seeds, with Azospirillum brasilense and nitrogen and molybdic fertilization, in cover, influence the agronomic characteristics and the productive yield of common beans. For this, a randomized block design was used, in a $2 \times 2 \times 2$ factorial scheme, with four replications. Seed inoculation (without inoculation and with inoculation of $A$. brasilense), foliar application of molybdenum (without application and with application of $126 \mathrm{~g}$ ha-1) and nitrogen coverage
\end{abstract}


(without application and with application of $30 \mathrm{~kg}$ ha-1). The trials were conducted in the municipality of Colorado do Oeste, Rondônia, in the years 2017 and 2018, adopting a system of direct seeding. The BRS Estilo cultivar was used and strains AbV5 and AbV6 with 2x108 Ufc $\mathrm{g}^{-1}$ for seed inoculation. Leaf molybdenum was applied, in a single dose, 19 days after seedling emergence and nitrogen, supplied during the R5 reproductive development phase, using urea as the source, applied manually in the planting line. The inoculation of bean seeds, with $A$. brasilense, results in increased productivity when associated with nitrogen fertilization in cover. Nitrogen fertilization in cover is determinant in increasing common bean productivity.

Key words: Nodulation. Rhizobia. Biological fixation. Inoculation. Molybdenum.

\section{INTRODUÇÃO}

O feijão comum (Phaseolus vulgaris L.), aqui referido simplesmente como feijão, é a espécie mais cultivada no mundo entre as demais do gênero Phaseolus, sendo o Brasil um dos maiores produtores e consumidores (Departamento de Pesquisas e Estudos Econômicos DEPEC, 2017; SANTOS et al., 2019). Este grão é um dos principais componentes da dieta alimentar brasileira, constituindo-se uma das principais e mais importantes fontes de proteína vegetal, em vários países, especialmente na América do Sul, Central e África (HUNGRIA; NOGUEIRA; ARAUJO, 2013; RIBEIRO et al., 2013). A cultura se destaca social e economicamente, sendo cultivado por pequenos e grandes produtores, em diversificados sistemas de produção (VALADÃO et al., 2009).

Dentre os fatores limitantes a produtividade da cultura, destaca-se a susceptibilidade das cultivares às doenças e o cultivo em solos de baixa fertilidade (VALADÃO et al., 2009). A busca por melhores rendimentos passa principalmente pela melhoria das características do solo e da nutrição vegetal, em especial da adubação nitrogenada. O nitrogênio (N) é considerado por inúmeros autores (OLIVEIRA et al., 2012) como um dos nutrientes requeridos em maior quantidade pelas diversas culturas, em especial as leguminosas anuais produtoras de grãos. Além do alto custo econômico de produção da cultura, há ainda um custo ecológico adicional pelo uso de adubos nitrogenados, considerando-se que em solos tropicais ocorrem grandes perdas dos fertilizantes aplicados, principalmente por lixiviação ou volatilização (FIGUEIREDO et al., 2016).

O feijoeiro, sendo uma leguminosa pode se beneficiar da associação simbiótica com bactérias do gênero Rhizobium (BASSAN et al., 2001). Essas bactérias são capazes de fixar o $\mathrm{N}$ atmosférico e fornecê-lo à cultura, por um mecanismo biológico capaz de substituir, ainda que parcialmente, a adubação nitrogenada, (HUNGRIA et al., 1997).

Porém, a diversidade de respostas da inoculação na cultura do feijão, quando comparada à outras leguminosas, como por exemplo a soja, leva a baixa utilização dessa técnica. Esse desempenho insatisfatório está relacionado a fatores genéticos e ambientais, e ainda ao processo de nodulação, considerado lento (CHAVERRA; GRAHAM, 1992). Oliveira, Araujo e Dutra (1996) observaram também, que rizóbios nativos, muitas vezes pouco eficientes na FBN, nodulam o feijoeiro e dificultam a introdução de estirpes mais eficientes. 
$\mathrm{Na}$ literatura existem vários trabalhos confirmando que o Azospirillum produz fitohormônios que estimulam o crescimento das raízes de diversas espécies de plantas (HUNGRIA; NOGUEIRA; ARAUJO, 2015; PERES et al., 2016). Esse grupo de rizobactérias podem ainda fixar $\mathrm{N}$ e disponibilizá-lo ao feijoeiro. Elas melhoram o crescimento das plantas e a aquisição de nutrientes, constituindo um recurso essencial para práticas agrícolas sustentáveis (BHISE; DANDGE, 2019). Assim, a utilização de Azospirillum pode melhorar o desempenho produtivo e a nodulação do feijoeiro, apresentando-se como alternativa. Essas rizobactérias benéficas podem estimular o crescimento das plantas sob condições de estresse, por mecanismos como a produção de fitormônios, exopolissacarídeos, sideróforo, ácidos orgânicos e fixação de nitrogênio (BHISE; BHAGWAT; DANDGE et al., 2017; GONTIAMISHRA et al., 2017).

Por outro lado, é possível também, por meio do manejo nutricional, aumentar a capacidade da FBN nessa cultura. Por exemplo o fornecimento de micronutrientes via foliar ou sobre a superfície das sementes. Entre estes micronutrientes, o molibdênio se destaca, por ser constituinte estrutural de pelo menos duas enzimas relacionadas ao metabolismo do $\mathrm{N}$, a nitrogenase e a nitrato redutase (OLIVEIRA; ARAUJO; DUTRA, 1996).

Desse modo, considerando a grande exigência do feijoeiro em nutrientes, em especial o nitrogênio, este estudo buscou avaliar se a inoculação de sementes, com Azospirillum brasilense e adubação nitrogenada e molíbdica, em cobertura, influenciam os caracteres agronômicos e o rendimento produtivo do feijão comum em condições amazônicas.

\section{MATERIAL E MÉTODOS}

\section{Localização Experimental e Características do Solo}

O trabalho foi instalado na área experimental de pesquisa pertencente ao Instituto Federal de Educação Ciência e Tecnologia de Rondônia, no município de Colorado do Oeste, situado no Cone Sul do Estado de Rondônia. Apresentando como coordenadas geográficas $60^{\circ} 32^{\prime}$ de longitude Leste de Greenwich e $13^{\circ}$ 07' de latitude Sul, com altitude de 460 metros. O clima conforme classificação de Köppen é do tipo Awa, tropical quente e úmido, com duas estações bem definidas. A temperatura média anual da região é de $23{ }^{\circ} \mathrm{C}$ e precipitação anual média de 2.400 mm (Secretaria de Estado do Desenvolvimento Ambiental - SEDAM, 2012).

O solo da área é classificado como ARGISSOLO VERMELHO ESCURO, o qual teve as características químicas determinadas antes da instalação do experimento, nas camadas de 0,00 a $0,20 \mathrm{~m}$, apresentando os seguintes valores: $\mathrm{pH} 4,4 ; \mathrm{P}\left(\mathrm{mg} \mathrm{dm}^{-3}\right) 5,0 ; \mathrm{K}\left(\mathrm{mmolc} \mathrm{dm}^{-3}\right)$

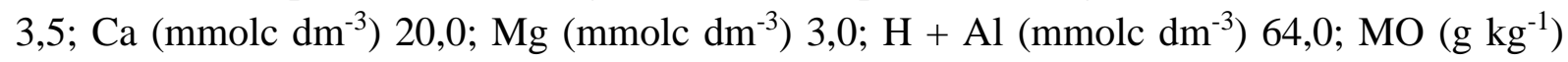
31,0. Quanto as características físicas, estas foram determinadas e os valores observados foram: areia $\left(\mathrm{g} \mathrm{kg}^{-1}\right) 566$; silte $\left(\mathrm{g} \mathrm{kg}^{-1}\right) 224$ e argila $\left(\mathrm{g} \mathrm{kg}^{-1}\right) 210$.

Com base nas características do solo na área experimental empregou-se na correção do solo, visando elevação de pH e saturação por bases, indicados para cultura do feijoeiro, utilizando calcário tipo Filler PRNT 100\% na dose de 3,7 toneladas por hectare. 


\section{Delineamento experimental e tratamentos}

O delineamento experimental empregado no experimento foi o de blocos casualizados disposto em um esquema fatorial $2 \times 2 \times 2$, em quatro repetições. Os tratamentos constituíram-se pela inoculação ou não de sementes de feijão BRS Estilo (Testemunha sem inoculação e inoculação com Azospirillum brasilense), a aplicação foliar de molibdênio (sem aplicação e com aplicação de $126 \mathrm{~g} \mathrm{ha}^{-1}$ ) e o fornecimento de nitrogênio em cobertura (sem aplicação e com aplicação de $30 \mathrm{~kg} \mathrm{ha}^{-1}$ ).

\section{Implantação e condução do experimento}

A cultivar utilizada foi a BRS Estilo, desenvolvida pela EMBRAPA, lançada em 2009 e indicada para cultivo em Rondônia. A cultivar apresenta arquitetura de plantas eretas, com resistência ao acamamento, sendo adaptada à colheita mecânica direta e apresentando ciclo normal (de 85 a 90 dias, da emergência à maturação fisiológica), considerada morfologicamente com pertencente ao grupo Tipo II, que relaciona o crescimento da planta como sendo de hábito indeterminado, arbustivo, porte ereto e caule pouco ramificado.

As estirpes utilizadas para a inoculação de A. brasilense foram AbV5 e AbV6 com $2 \times 10^{8} \mathrm{Ufc} / \mathrm{g}$, obtidas de produtos comerciais registrados no Ministério da Agricultura e Pecuária.

Cada unidade experimental $\left(12,5 \mathrm{~m}^{2}\right)$ foi constituída de 5 linhas de $5 \mathrm{~m}$ de comprimento, espaçadas de $0,5 \mathrm{~m}$ e a área útil correspondente as 3 linhas centrais, desprezando-se 0,5 metros, em ambas as extremidades de cada linha. A semeadura, foi efetuada manualmente em sulcos, distribuindo-se 15 sementes por metro, na profundidade de 3 a $4 \mathrm{~cm}$.

O tratamento químico das sementes foi realizado utilizando produto comercial contendo uma mistura de inseticida (fipronil), e fungicidas (tiofanato-metílico e piraclostrobina), na dosagem de $200 \mathrm{ml}$ produto comercial/100 kg de sementes.

A inoculação das sementes foi realizada à sombra, após prévio tratamento químico e uma breve secagem do produto aplicado (para evitar danos às sementes), momentos antes da semeadura, nas doses recomendadas de Azospirillum brasilense $(100 \mathrm{ml}$ para cada $50 \mathrm{~kg}$ de sementes).

Todas as parcelas receberam adubação de base equivalente a $10 \mathrm{~kg} \mathrm{ha}^{-1}$ de nitrogênio (sulfato de amônio), $90 \mathrm{~kg} \mathrm{ha}^{-1}$ de $\mathrm{P}_{2} \mathrm{O}_{5}$ (superfosfato triplo) e $20 \mathrm{~kg} \mathrm{ha}^{-1}$ de $\mathrm{K}_{2} \mathrm{O}$ (cloreto de potássio), conforme recomendação realizada de acordo com as características químicas do solo e a faixa de produtividade esperada. Estes fertilizantes foram distribuídos manualmente após o sulcamento.

O controle das plantas invasoras, das pragas e doenças foi realizado de acordo com o nível de infestação das mesmas. A aplicação de defensivos bem como do molibdênio, foi promovida com o uso de um pulverizador costal de pressão constante, com capacidade para 20 L. O controle de pragas no cultivo foi feito através de pulverização, com a utilização do inseticida tiametoxam, inseticida sistêmico de contato e ingestão do grupo químico neonicotinóide (125 $\left.\mathrm{mL} \mathrm{ha}^{-1}\right)$. 
Todas as unidades experimentais receberam irrigação complementar por gotejamento a partir do final do período chuvoso. Esse método de irrigação, mesmo não muito recomendado para culturas anuais produtoras de grãos, foi utilizado tendo em vista reduzir problemas fitossanitários que por ventura viesse acometer a cultura durante seu desenvolvimento.

O molibdênio foi fornecido na dose estimada para a região de acordo com Melo Filho et al. (126 $\left.\mathrm{g} \mathrm{ha}^{-1}\right)$ e aplicado via foliar, uma única vez, aos 19 dias após a emergência das plântulas (DAE). Utilizou-se para aplicação pulverizador costal manual e com bico tipo leque.

O nitrogênio em cobertura foi fornecido por ocasião da fase de desenvolvimento reprodutivo R5 (botões florais formados) utilizando-se como fonte de nitrogênio a ureia. A aplicação foi realizada manualmente, distribuindo o fertilizante sob o dossel das plantas na linha de plantio.

\section{Variáveis analisadas}

Durante execução do experimento algumas características agronômicas e componentes de produção foram mensurados. Dentre elas estão: população final de plantas, número de vagens por planta, número médio de grãos por vagem e a massa de 100 grãos, e ainda o rendimento de grãos.

Por ocasião da colheita avaliou-se, em duas linhas, na área útil das parcelas, o número de plantas com o objetivo de se calcular a população final de plantas ha ${ }^{-1}$. Foram coletadas, posteriormente, 10 plantas na área útil das parcelas para a avaliação de: número de vagens por planta (determinado através da relação do número total de vagens/número de plantas); número médio de grãos por vagem (calculado através da relação do número total de grãos/número total de vagens); massa de 100 grãos (obtido através da coleta ao acaso e pesagem de amostras de 100 grãos por parcela).

As plantas da área útil de cada parcela foram arrancadas e deixadas para secagem a pleno sol. Após a secagem, as mesmas foram submetidas a trilha manual, os grãos pesados e os resultados extrapolados para $\mathrm{kg} \mathrm{ha}^{-1}$ (a $16 \%$ base úmida);

\section{Análise estatística dos dados}

Os dados foram submetidos à análise de variância, sendo as médias dos diferentes tratamentos comparadas pelo teste de Tukey, a 5\% de probabilidade, utilizando-se o programa estatístico SISVAR.

\section{RESULTADOS E DISCUSSÃO}

A Tabela 1 apresenta os valores médios e análise de variância para população final de plantas e componentes de produção de feijão de inverno, em função da inoculação de sementes, aplicação foliar de molibdênio e nitrogênio em cobertura, em dois anos de cultivo, 2017 e 2018.

Pouca alteração na população final de plantas entre os tratamentos envolvendo ou não aplicação de molibdênio via foliar $\left(126 \mathrm{~g} \mathrm{ha}^{-1}\right)$ e nitrogênio em cobertura $\left(30 \mathrm{~kg} \mathrm{ha}^{-1}\right)$ foram 
verificados em ambos os cultivos. Por outro lado, no primeiro ano de cultivo (2017), houve um incremento no estande final de plantas no tratamento que recebeu inoculação de Azospirillum brasilense em detrimento a testemunha sem inoculação (Tabela 1). De maneira geral, maior estande final de plantas foi observado no primeiro cultivo, independente do tratamento. No segundo cultivo (2018), houve uma menor variação na população final de plantas entre os tratamentos, possivelmente por fatores ambientais, além da maior população de rizóbios na área.

Tabela 1. População de plantas e componentes de produção de feijão de inverno, em função da inoculação de sementes, aplicação foliar de molibdênio e nitrogênio em cobertura, cultivos de 2017 e 2018. Plant population and production components of winter bean, as a function of seed inoculation, foliar application of molybdenum and nitrogen in cover crops, 2017 and 2018 crops.

\begin{tabular}{|c|c|c|c|c|c|c|c|c|}
\hline \multirow[t]{2}{*}{ Tratamentos } & \multicolumn{2}{|c|}{$\begin{array}{c}\text { População Final } \\
\text { plantas ha }^{-1}\end{array}$} & \multicolumn{2}{|c|}{$\begin{array}{c}\text { Vagens } \\
\text { planta }^{-1}\end{array}$} & \multicolumn{2}{|c|}{$\begin{array}{c}\text { Grãos } \\
\text { vagem }^{-1}\end{array}$} & \multicolumn{2}{|c|}{$\begin{array}{l}\text { Massa de } 100 \\
\text { grãos (g) }\end{array}$} \\
\hline & 2017 & 2018 & 2017 & 2018 & 2017 & 2018 & 2017 & 2018 \\
\hline \multicolumn{9}{|l|}{ Inoculação (I) } \\
\hline Testemunha & $240.104 b$ & $205.937 \mathrm{a}$ & $8,58 \mathrm{a}$ & $16,6 a$ & $4,45 \mathrm{a}$ & $4,41 \mathrm{a}$ & $33,99 \mathrm{a}$ & $33,07 \mathrm{a}$ \\
\hline A. brasilense & $258.541 \mathrm{a}$ & $203.229 a$ & $8,10 \mathrm{a}$ & $15,6 \mathrm{a}$ & $4,21 \mathrm{a}$ & $4,57 \mathrm{a}$ & $33,34 a$ & $33,68 \mathrm{a}$ \\
\hline \multicolumn{9}{|l|}{ Molibdênio $(M o)$} \\
\hline $0 \mathrm{~g} \mathrm{ha}^{-1}$ & $248.958 \mathrm{a}$ & $206.145 a$ & $8,70 \mathrm{a}$ & $15,72 \mathrm{a}$ & $4,37 \mathrm{a}$ & $4,60 \mathrm{a}$ & $33,25 \mathrm{a}$ & $33,21 \mathrm{a}$ \\
\hline $126 \mathrm{~g} \mathrm{ha}^{-1}$ & $249.687 \mathrm{a}$ & $203.020 \mathrm{a}$ & $7,97 \mathrm{a}$ & $16,52 \mathrm{a}$ & $4,29 \mathrm{a}$ & $4,38 \mathrm{a}$ & $34,08 \mathrm{a}$ & $33,54 \mathrm{a}$ \\
\hline \multicolumn{9}{|l|}{ Nitrogênio $(N)$} \\
\hline $0 \mathrm{~kg} \mathrm{ha}^{-1}$ & $247.708 \mathrm{a}$ & $204.374 a$ & $7,20 \mathrm{~b}$ & $16,02 \mathrm{a}$ & $4,36 \mathrm{a}$ & $4,57 \mathrm{a}$ & $33,77 \mathrm{a}$ & $33,43 a$ \\
\hline $30 \mathrm{~kg} \mathrm{ha}^{-1}$ & $250.937 \mathrm{a}$ & $204.791 \mathrm{a}$ & $9,48 \mathrm{a}$ & $16,23 \mathrm{a}$ & $4,30 \mathrm{a}$ & $4,40 \mathrm{a}$ & $33,56 \mathrm{a}$ & $33,32 \mathrm{a}$ \\
\hline \multicolumn{9}{|l|}{ Teste F (Fc) } \\
\hline $\mathrm{I}$ & $4,53^{*}$ & $0,38^{\text {ns }}$ & $0,30^{\text {ns }}$ & $1,20^{\text {ns }}$ & $2,55^{\text {ns }}$ & $0,92^{\text {ns }}$ & $0,86^{\mathrm{ns}}$ & $2,10^{\mathrm{ns}}$ \\
\hline Mo & $0,01^{\mathrm{ns}}$ & $0,51^{\mathrm{ns}}$ & $0,69^{\text {ns }}$ & $0,68^{\mathrm{ns}}$ & $0,26^{\mathrm{ns}}$ & $1,58^{\text {ns }}$ & $1,45^{\mathrm{ns}}$ & $0,59^{\mathrm{ns}}$ \\
\hline $\mathrm{N}$ & $0,13^{\text {ns }}$ & $0,01^{\mathrm{ns}}$ & $6,73^{*}$ & $0,04^{\mathrm{ns}}$ & $0,18^{\text {ns }}$ & $0,89^{\text {ns }}$ & $0,09^{\text {ns }}$ & $0,07^{\mathrm{ns}}$ \\
\hline I x Mo & $0,53^{\mathrm{ns}}$ & $0,91^{\mathrm{ns}}$ & $0,62^{\mathrm{ns}}$ & $0,88^{\mathrm{ns}}$ & $4,02^{\text {ns }}$ & $0,03^{\text {ns }}$ & $0,81^{\mathrm{ns}}$ & $0,01^{\mathrm{ns}}$ \\
\hline I x N & $1,97 *$ & $1,42^{\mathrm{ns}}$ & $0,01^{\mathrm{ns}}$ & $0,72^{\mathrm{ns}}$ & $0,33^{\text {ns }}$ & $3,31^{\mathrm{ns}}$ & $1,26^{\mathrm{ns}}$ & $0,63^{\mathrm{ns}}$ \\
\hline $\operatorname{Mo} \times \mathrm{N}$ & $0,81^{\mathrm{ns}}$ & $1,00^{\mathrm{ns}}$ & $4,58^{*}$ & $0,08^{\mathrm{ns}}$ & $0,22^{\mathrm{ns}}$ & $0,28^{\text {ns }}$ & $0,47^{\mathrm{ns}}$ & $0,54^{\mathrm{ns}}$ \\
\hline I x Mo x N & $0,09^{\text {ns }}$ & $0,91^{\mathrm{ns}}$ & $1,18^{\mathrm{ns}}$ & $0,01^{\mathrm{ns}}$ & $0,43^{\text {ns }}$ & $2,00^{\text {ns }}$ & $0,22^{\mathrm{ns}}$ & $1,18^{\mathrm{ns}}$ \\
\hline \multicolumn{9}{|l|}{ DMS (5\%) } \\
\hline Inoculação & $18.015,75$ & - & - & - & - & - & - & - \\
\hline Molibdênio & - & - & - & - & - & - & - & - \\
\hline Nitrogênio & - & - & 1,82 & - & - & - & - & - \\
\hline CV (\%) & 9,83 & 6,04 & 29,80 & 16,98 & 9,61 & 11,08 & 5,83 & 3,59 \\
\hline
\end{tabular}

Nota: $* P<0.05 ; * * P<0.001$ pelo teste $\mathrm{F}$; DMS $=$ diferença mínima significativa; $\mathrm{CV}=$ coeficiente de variação. Médias seguidas de mesma letra não diferem estatisticamente (Tukey, $\mathrm{p}>0,05$ ). $* P<0.05$; $* * P<$ 0.001 by the F test; MSD = minimum significant difference $C V=$ coefficient of variation. Averages followed by the same letter do not differ statistically (Tukey, $p>0.05$ ).

Fonte: Autoria própria. Own authorship.

O número médio de vagens por planta, no cultivo de 2017 , foi de 8,34 vagens, componente influenciado $(P<0,05)$ pela aplicação de $\mathrm{N}$ em cobertura e pela interação entre $\mathrm{N}$ em cobertura e Mo via foliar (Tabela 1). A adubação nitrogenada proporcionou efeito 
positivo sobre o número de vagens por planta, de modo que, com a aplicação de $30 \mathrm{~kg} \mathrm{ha}^{-1} \mathrm{de}$ $\mathrm{N}$ em cobertura, um maior número de médio de vagens por planta foi obtido $(9,48)$, quando comparado ao tratamento sem adubação de cobertura $(7,20)$. Essa diferença de pouco mais de 2 vagens a mais por planta, obtida com fornecimento de $\mathrm{N}$ em cobertura, promoveu no mesmo tratamento, um incremento na produtividade de grãos. A inoculação das sementes e aplicação de molibdênio não afetaram significativamente quando em tratamentos isolados. Um aumento considerável no número de vagens foi observado no segundo cultivo (2018). Em média o número de vagens no segundo ano foi de 16,12 vagens, cerca de $48 \%$ superior ao primeiro cultivo. Porém, não se verificou diferença significativa entre os fatores.

Não foi constatado efeito de nenhuma das fontes de variação, avaliadas nestes ensaios, sobre o número de grãos por vagem, que foi de em média 4,33 e 4,49 grãos por vagem, no primeiro e segundo cultivo, respectivamente (Tabela 1). Em síntese, os resultados foram semelhantes entre os tratamentos e entre os cultivos. $O$ que pode estar vinculada à característica varietal do feijoeiro comum.

De maneira similar, a massa média de 100 grãos não foi afetada por nenhuma das fontes de variação, verificando-se no ensaio uma média de 33,66 g no primeiro cultivo e 33,37 g no segundo (16\% umidade). Confirmando que essa é uma característica que apresenta pouca variação em virtude das alterações do meio.

Quanto a produtividade de grãos, verificou-se no primeiro cultivo uma média de 2.728 $\mathrm{kg} \mathrm{ha}^{-1}$, bastante superior à média nacional $\left(1.158 \mathrm{~kg} \mathrm{ha}^{-1}\right)$ e principalmente a do estado de Rondônia (970 kg ha-1), estimadas pela Companhia Nacional de Abastecimento na safra 2016/17 (CONAB, 2017). O rendimento médio verificado no ensaio foi 57\% superior à média brasileira e cerca 64\% superior à média do estado de Rondônia. No segundo cultivo, a produtividade foi ainda superior, apresentando uma média de $3.031 \mathrm{~kg} \mathrm{ha}^{-1}$. Esse incremento em produtividade deve-se principalmente ao aumento no número de vagens por planta, apresentado acima.

A inoculação das sementes, com A. brasilense, não proporcionou, de forma isolada, incrementos no rendimento de grãos da cultura no presente estudo, ainda assim, resultado superior (3.102 $\mathrm{kg} \mathrm{ha}^{-1}$ ), mesmo que não diferente estatisticamente, foi observado com a inoculação das sementes.

Os tratamentos com molibdênio apresentaram rendimento de grãos apenas 5,3\% superior ao tratamento com ausência de molibdênio foliar, não influenciando significativamente os resultados obtidos (Figura 1). Ainda assim, o incremento registrado com fornecimento de molibdênio via foliar (126 $\mathrm{g} \mathrm{ha}^{-1}$ ), equivale a cerca de $149 \mathrm{~kg} \mathrm{ha}^{-1}$, ou seja, aproximadamente 2,48 sacas $\mathrm{ha}^{-1}$, incremento bastante significativo levando em conta o cultivo em áreas extensas.

Quanto à utilização de nitrogênio em cobertura, verificou-se efeito na produtividade, de maneira que o resultado superior $\left(2.889 \mathrm{~kg} \mathrm{ha}^{-1}\right)$ foi obtido com aplicação de $30 \mathrm{~kg} \mathrm{ha} \mathrm{ha}^{-1}$ nitrogênio em cobertura, o que representa um incremento de $310 \mathrm{~kg} \mathrm{ha}^{-1}(10,7 \%)$ em relação ao tratamento que não recebeu adubação nitrogenada em cobertura. Quanto a inoculação das sementes, esta não proporcionou, de forma isolada, incrementos no rendimento de grãos da 
cultura no presente estudo.

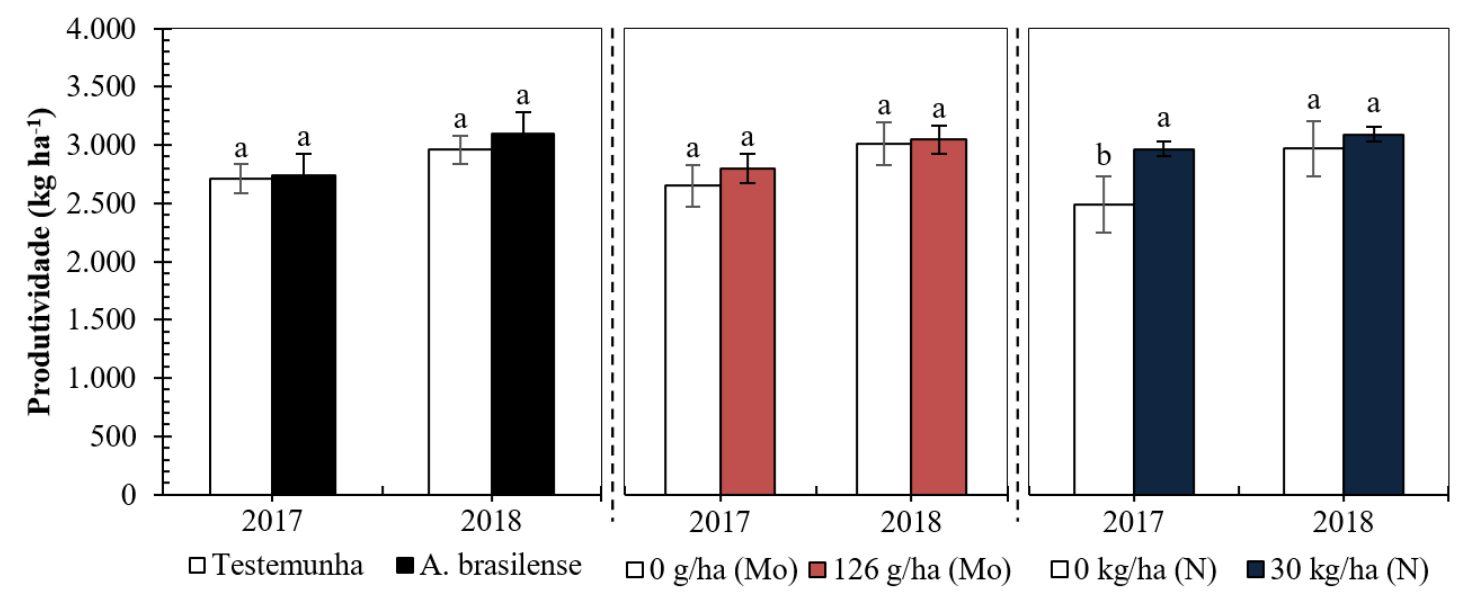

Médias seguidas de mesma letra, para o mesmo ano (em cada variável), não diferem entre si pelo teste de Tukey. Mo = Molibdênio; N = Nitrogênio. Means followed by the same letter, for the same year (in each variable), do not differ from each other by the Tukey test. Mo = Molybdenum; $N=$ Nitrogen.

Figura 1. Efeito da inoculação de sementes com A. brasilense, aplicação de molibdênio via foliar e adução nitrogenada em cobertura na produtividade do feijão de inverno, cultivos de 2017 e 2018. Effect of seed inoculation with A. brasilense, leaf application of molybdenum and cover nitrogen addition on winter bean application, cultivated from 2017 and 2018. Fonte: Autoria própria. Own authorship.

Tabela 2. Interação inoculação de sementes e nitrogênio em cobertura para população final de plantas e produtividade no feijoeiro de inverno em condições amazônicas, 2017. Seed and nitrogen inoculation interaction in cover for final plant population and yield in winter bean under Amazonian conditions, 2017.

\begin{tabular}{ccc}
\hline Inoculação de sementes & \multicolumn{2}{c}{ Nitrogênio em cobertura } \\
\hline & \multicolumn{2}{c}{ População de plantas (plantas ha-1) } \\
& $0 \mathrm{~kg} \mathrm{ha}^{-1}$ & $30 \mathrm{~kg} \mathrm{ha}^{-1}$ \\
\cline { 2 - 3 } Testemunha & $244.583 \mathrm{aA}$ & $235.625 \mathrm{bA}$ \\
Azospirillum brasilense & $250.833 \mathrm{aA}$ & $266.250 \mathrm{aA}$ \\
\hline & \multicolumn{2}{c}{ Produtividade $\left(\mathrm{kg} \mathrm{ha}^{-1}\right)$} \\
Testemunha & $0 \mathrm{~kg} \mathrm{ha}^{-1}$ & $30 \mathrm{~kg} \mathrm{ha}^{-1}$ \\
\hline Azospirillum brasilens & $2.534 \mathrm{aB}$ & $2.890 \mathrm{aA}$ \\
\cline { 2 - 3 } & $2.444 \mathrm{aB}$ & $3.045 \mathrm{aA}$ \\
\hline
\end{tabular}

Nota: Médias seguidas de mesma letra, minúsculas nas colunas e maiúsculas nas linhas, não diferem estatisticamente entre si pelo teste de Tukey a $5 \%$ de probabilidade. Averages followed by the same letter, lower case in the columns and upper case in the rows, do not differ statistically by the Tukey test at 5\% probability.

Fonte: Autoria própria. Own authorship.

No primeiro cultivo (2017), diferente do ano seguinte, houve interações significativas entre inoculação de sementes e adubação nitrogenada em cobertura para as variáveis população final de plantas e produtividade de grãos do feijoeiro $(P<0,05)$ e os desdobramentos encontram-se nas tabelas 2. Analisando o desdobramento, não houve diferença significativa da ausência ou presença de nitrogênio em cobertura, quando as sementes foram ou não inoculadas. Contudo, na presença de nitrogênio em cobertura, maior estande final de plantas foi conseguido com a inoculação das sementes (266.250 plantas ha $\left.{ }^{-1}\right)$, 
em detrimento aos demais tratamentos (Tabela 2).

No que se refere a produtividade de grãos do feijoeiro em função da inoculação de sementes e aplicação de nitrogênio em cobertura, esta foi influenciada significativamente (Tabla 2). Mediante desdobramento da interação, verifica-se que a inoculação das sementes com Azospirillum proporcionou aumento da produtividade, atingindo valor de $3.045 \mathrm{~kg} \mathrm{ha}^{-1}$, na presença de adubação nitrogenada, se configurando o melhor dentre os tratamentos avaliados neste ensaio.

Com relação a variável vagens por planta, também apenas no primeiro cultivo, nota-se que, houve interação significativa entre nitrogênio em cobertura e molibdênio foliar e o desdobramento encontra-se na Tabela 3.

Tabela 3. Interação adubação molíbdica foliar e nitrogênio em cobertura para número de vagens por planta e produtividade do feijão de inverno em condições amazônicas, 2017. Interaction leaf foliar and nitrogen fertilization in cover for number of pods per plant and winter bean yield under Amazonian conditions, 2017.

\begin{tabular}{ccc}
\hline Molibdênio foliar & \multicolumn{2}{c}{ Nitrogênio em cobertura } \\
\hline & \multicolumn{2}{c}{ Número de vagens planta $^{-1}$} \\
& $0 \mathrm{~kg} \mathrm{ha}^{-1}$ & $0 \mathrm{~kg} \mathrm{ha}^{-1}$ \\
\cline { 2 - 3 } $126 \mathrm{~g} \mathrm{ha} \mathrm{ha}^{-1}$ & $6,62 \mathrm{aB}$ & $10,78 \mathrm{aA}$ \\
& $7,77 \mathrm{aA}$ & $8,17 \mathrm{bA}$ \\
\hline $0 \mathrm{~g} \mathrm{ha}^{-1}$ & \multicolumn{2}{c}{ Produtividade $\left(\mathrm{kg} \mathrm{ha}^{-1}\right)$} \\
$126 \mathrm{~g} \mathrm{ha}^{-1}$ & $0 \mathrm{~kg} \mathrm{ha}^{-1}$ & $30 \mathrm{~kg} \mathrm{ha}^{-1}$ \\
\hline & $2.353 \mathrm{bB}$ & $2.953 \mathrm{aA}$ \\
& $2.624 \mathrm{aB}$ & $2.980 \mathrm{aA}$ \\
\hline
\end{tabular}

Nota: Médias seguidas de mesma letra, minúsculas nas colunas e maiúsculas nas linhas, não diferem estatisticamente entre si pelo teste de Tukey a $5 \%$ de probabilidade. Averages followed by the same letter, lower case in the columns and upper case in the rows, do not differ statistically by the Tukey test at 5\% probability.

Fonte: Autoria própria. Sourve: Own authorship.

Os maiores valores foram obtidos com adubação nitrogenada na ausência de molibdênio via foliar $\left(10,78\right.$ vagens planta $\left.^{-1}\right)$. Percebe-se ainda, que na ausência de nitrogênio em cobertura, os resultados são semelhantes com e sem aplicação de molibdênio. Por outro lado, com a aplicação de molibdênio foliar, independente da presença ou não de nitrogênio em cobertura os valores para vagens por planta são estatisticamente iguais entre os tratamentos, porém inferiores aos obtidos com nitrogênio na ausência de molibdênio.

De forma análoga ao número de vagens por planta, a produtividade de grãos também foi influenciada pela interação entre os fatores N e Mo. No desdobramento da interação (Tabela 3), constata-se que de maneira geral, a aplicação de nitrogênio em cobertura contribuiu para o incremento na produtividade da cultura, principalmente quando não houve aplicação de molibdênio. Verifica-se que o Mo em aplicação foliar foi determinante no aumento do efeito do N sobre a produtividade de grãos do feijoeiro. De modo que a aplicação do micronutriente via foliar proporcionou maior eficiência de utilização do $\mathrm{N}$, promovendo um incremento de cerca de $271 \mathrm{~kg} \mathrm{ha}^{-1}$ no rendimento da cultura, passando de $2.353 \mathrm{~kg} \mathrm{ha}^{-1}$ para $2.624 \mathrm{~kg} \mathrm{ha}^{-1}$ com aplicação foliar de molibdênio, mesmo na ausência de adubação nitrogenada. Também 
houve incremento com aplicação de Mo, porém não significativo estatisticamente, na presença de adubação nitrogenada em cobertura, na ordem de $27 \mathrm{~kg} \mathrm{ha}^{-1}$.

Nota-se que o fornecimento de nitrogênio $\left(30 \mathrm{~kg} \mathrm{ha}^{-1}\right)$ em cobertura, foi determinante no incremento em produtividade, de modo que, independente da inoculação das sementes e da aplicação de molibdênios via foliar, o rendimento de grãos foi superior na presença de nitrogênio.

No presente trabalho, pouco se alterou a população final de plantas entre os tratamentos envolvendo aplicação de molibdênio via foliar e nitrogênio em cobertura. Ainda assim, no primeiro cultivo houve um incremento no estande final de plantas para tratamento que recebeu inoculação de Azospirillum brasilense. De maneira geral, maior estande final de plantas foi observado no primeiro cultivo. Romanini Junior et al. (2007) em Selvíria (MS) no ano de 2002 e 2003 verificaram que houve influência da inoculação para população de plantas, apenas no segundo ano de cultivo, de modo que a presença da inoculação contribuiu para maior população final de plantas. Já Melo Filho (2011) constatou incremento no estande final com a aplicação foliar de molibdênio 20 dias após emergência das plântulas.

A inoculação das semente e aplicação de molibdênio não afetaram significativamente quando em tratamentos isolados, o número de vagens por planta. Segundo Arf et al. (1996), o número de vagens é o primeiro componente do rendimento a ser definido na fase reprodutiva, sendo desse modo, mais facilmente afetado pela variação da população de plantas, devido ao ambiente de competição. Nos estudos de Corsini (2014), analisando a inoculação de sementes, observou-se que a coinoculação de A. brasilense com $R$. tropici proporcionou às plantas de feijão maior número de vagens quando comparado à testemunha. Melo Filho (2011) em trabalho desenvolvido na mesma localidade, evidenciou incremento no número de vagens por planta com aplicação de molibdênio foliar, até a dose estimada de $60 \mathrm{~g} \mathrm{ha}^{-1}$. Porém, o mesmo autor relata tendência de queda desse componente de produção a partir desta dose, corroborando com o presente trabalho, onde a aplicação de $126 \mathrm{~g} \mathrm{ha}^{-1}$ não promoveu resultados diferentes dos encontrados sem adubação molíbdica.

Como plantas de feijão bem nutridas em nitrogênio produzem mais flores e, consequentemente, mais vagens por plantas, com acréscimos também no número de óvulos fertilizados por vagem (PORTES, 1996), infere-se que os tratamentos sem aplicação de nitrogênio em cobertura não supriram as demandas de nitrogênio da forma semelhante à do tratamento adubado com $30 \mathrm{~kg} \mathrm{ha}^{-1}$ de $\mathrm{N}$. Estes resultados corroboram aos obtidos por outros autores, como por exemplo, os de Soratto, Carvalho e Arf (2004) e Moreira et al. (2013). Porém, Romanini Junior et al. (2007), Valadão et al. (2009), Figueiredo (2016) e Corsini (2014), não constataram influência significativa sobre o número de vagens por planta quando da aplicação de nitrogênio em cobertura.

Diferente dos resultados de Valadão et al. (2009) e Corsini (2014), que demostram influência da interação entre inoculação de semente, Mo e $\mathrm{N}$ das adubações sobre o número de grãos por vagem, o presente trabalho não constatou efeito de nenhuma das fontes de variação sobre esta variável em nenhum dos cultivos, o que pode estar vinculada à característica varietal do feijoeiro comum. Segundo Soratto, Carvalho e Arf (2004) a aplicação de $\mathrm{N}$ em cobertura não ocasiona grande variação no número de grãos por vagem 
provavelmente por se tratar de uma característica pouco influenciada pela adubação, mais sim, por outros fatores, como a densidade de semeadura e a radiação solar (CRUSCIOL et al., 2007, GOMES JÚNIOR; SÁ; VALÉRIO FILHO, 2008).

A massa média de 100 grãos, não afetada significativamente por nenhum dos fatores e interações, confirma que essa é uma característica que apresenta pouca variação em virtude das alterações do meio. Semelhante a resultados foram observados por Ferreira et al. (2000) com a cv. IAC Carioca e Kaneko et al. (2010) com a cv. Pérola, que não verificaram diferenças significativas na massa de 100 sementes entre os tratamentos com e sem inoculação de sementes. Estes resultados corroboram ainda com os obtidos por Soratto, Carvalho e Arf (2004), em que a aplicação de N não causou grande variação na massa de 100 grãos. A aplicação de molibdênio via foliar, também não proporcionou sobre a cultura reflexos quanto a massa de seus grãos, resultado deferente do apresentado por Leite (2004) e Melo Filho (2011), que constataram influência significativa da aplicação de molibdênio sobre o comportamento da massa de 1.000 sementes, de modo que, com a adubação molíbdica maiores valores de massas foram obtidos em relação àqueles produzidos sem adubação. Valadão et al. (2009), indica ainda influência da interação Mo x N sobre a massa de 100 grãos.

A produtividade média, elevada nestes ensaios, principalmente no segundo cultivo, foi notadamente influenciada pela aplicação de nitrogênio em cobertura. Incrementos no rendimento de grãos com adubação nitrogenada em cobertura também foram observados por Romanini Júnior et al. (2007). Provavelmente, deve-se esse incremento ao número de vagens por planta, que também foi maior neste tratamento (com nitrogênio), e Didonet e Vitória (2006) explica que, o número de vagens por planta, além de número de sementes por vagem e a massa das sementes são caracteres determinantes na produtividade final da cultura.

Os tratamentos com molibdênio apresentaram rendimento de grãos pouco superior ao tratamento ausente em molibdênio foliar, não influenciando significativamente os resultados obtidos. Estes resultados discordam dos verificados por Melo Filho (2011), que com a mesma dose de molibdênio (126 $\left.\mathrm{g} \mathrm{ha}^{-1}\right)$, aplicada via foliar, constatou incremento significativo no rendimento de grãos das cultivares Carioca e rosinha. Pessoa et al. (2000), Jesus Júnior et al. (2004) e Oliveira, Pelá e Pelá (2017) também obtiveram aumento da produtividade do feijoeiro com a aplicação de Mo via foliar. Independente da aplicação ou não de molibdênio via foliar na cultura, a adubação nitrogenada proporcionou incremento significativo na produtividade, discordando do constatado por Biscaro et al. (2011), que observaram incremento na produtividade do feijoeiro somente quando aplicação de $\mathrm{N}$ foi combinada com a aplicação de Mo via foliar.

Quanto a inoculação das sementes, esta não proporcionou, de forma isolada, incrementos no rendimento de grãos da cultura no presente estudo, corroborando com os resultados verificados por Corsini (2014). Diferentes resultados foram observados por Romanini Junior et al. (2007), que contataram aumentos na produtividade de feijoeiro com a inoculação de sementes. Porém, mediante desdobramento da interação, verifica-se que a inoculação das sementes com Azospirillum proporcionou aumento da produtividade, atingindo valor de $3.045 \mathrm{~kg} \mathrm{ha}^{-1}$, na presença de adubação nitrogenada, se configurando o melhor dentre 
os tratamentos avaliados neste ensaio. Segundo Hungria (2011) o maior desenvolvimento das raízes pela inoculação com Azospirillum pode implicar em incrementos na absorção da água e minerais, maior tolerância a estresses como salinidade e seca, resultando em uma planta mais vigorosa e produtiva.

\section{CONCLUSÃO}

A inoculação das sementes de feijão de inverno, com Azospirillum brasilense, melhora o desempenho das plantas e resulta em aumento da produtividade quando associada a adubação nitrogenada em cobertura.

A adubação nitrogenada em cobertura é determinante no aumento de produtividade do feijão de inverno, independentemente da inoculação com bactérias diazotróficas e/ou aplicação de Molibdênio foliar.

$\mathrm{Na}$ ausência de adubação nitrogenada em cobertura, aplicar molibdênio via foliar proporciona incremento na produtividade da cultura do feijão.

\section{AGRADECIMENTOS}

Os autores agradecem ao Instituto Federal de Rondônia, campus Colorado do Oeste, pelo apoio em infraestrutura e equipamentos utilizados para execução da pesquisa. Ao CNPq, pela concessão de bolsas e apoio financeiro para aquisição de materiais de consumo.

\section{REFERÊNCIAS BIBLIOGRÁFICAS}

ARF, O.; SÁ, M. E.; OKITA, C. S.; TIBA, M. A.; GUERREIRO NETO, G.; OGASSAWARA, F. Y. Efeito de diferentes espaçamentos e densidades de semeadura sobre o desenvolvimento do feijoeiro (Phaseolus vulgaris L.). Pesquisa Agropecuária Brasileira, Brasília, v. 31, n. 9, p.629-634, 1996.

BASSAN, D. A. Z.; ARF, O.; BUZETTI, S.; CARVALHO, M. A. C.; SANTOS, N. C. B.; SÁ, M. E. Inoculação de sementes e aplicação de nitrogênio e molibdênio na cultura do feijão de inverno: Produção e qualidade fisiológica de sementes. Revista Brasileira de Sementes, Londrina, v. 23, n. 1, p.76-83, 2001.

BHISE, K. K.; BHAGWAT, P. K.; DANDGE, P. B. Plant Growth-Promoting Characteristics of Salt Tolerant Enterobacter cloacae Strain KBPD and Its Efficacy in Amelioration of Salt Stress in Vigna radiata L. Journal of Plant Growth Regulation, [s. l.], v. 36, n. 1, p.215226, 2017. Disponível em: https://doi.org/10.1007/s00344-016-9631-0. Acesso em: 10 fev. 2020.

BHISE, K. K.; DANDGE, P. B. Mitigation of salinity stress in plants using plant growth promoting bacteria. Symbiosis, [s. l.], v. 79, n. 3, p.191-204, 2019. Disponível em: https://doi.org/10.1007/s13199-019-00638-y. Acesso em: 5 fev. 2020.

BISCARO, G. A.; FREITAS JUNIOR, N. A.; SORATTO, R. P.; KIKUTI, H.; JUNIOR, S. A. 
R. G.; \& AGUIRRE, W. M. Nitrogênio em cobertura e molibdênio via foliar no feijoeiro cultivado em solo de cerrado. Acta Scientiarum Agronomy, Maringá, v. 33, n. 4, p.665-670, 2011. Disponível em: DOI: http://dx.doi.org/10.4025/actasciagron.v33i4.6387. Acesso em: 2 fev. 2020.

CHAVERRA, M. H; GRAHAM, P. H. Cultivar variation in traits affecting early nodulation of common bean. Crop Science, Madison, v. 32, n. 6, p.1432-1436, 1992. Disponível em: DOI: http://dx.doi.org/10.2135/cropsci1992.0011183X003200060024x. Acesso em: 15 jan. 2020.

COMPANHIA NACIONAL DE ABASTECIMENTO - CONAB. Acompanhamento da safra brasileira: grãos: Safra 2016/17. Brasília, DF: CONAB, 2017. Disponível em: http://www.conab.gov.br. Acesso em: 15 fev. 2018.

CORSINI, D. C. D. C. Inoculação de sementes com Azospirillum brasilense e Rhizobium tropici e adubação nitrogenada em cobertura em feijoeiro de inverno irrigado em sistema plantio direto. 2014. 77 f. Dissertação (Mestrado em Agronomia), Faculdade de Engenharia, Universidade Estadual Paulista, Ilha Solteira, 2014.

CRUSCIOL, C. A. C.; SORATTO, R. P.; SILVA, L. M.; LEMOS, L. B. Fontes e doses de nitrogênio para o feijoeiro em sucessão a gramíneas no sistema plantio direto. Revista Brasileira de Ciência do Solo, Viçosa, v. 31, n. 6, p.1545-1552, 2007. Disponível em: DOI: http://dx.doi.org/10.1590/S0100-068320070006 00031. Acesso em: 10 jan. 2020.

DEPARTAMENTO DE PESQUISAS E ESTUDOS ECONÔMICOS - DEPEC. Feijão. 2017. Disponível em: https://www.economiaemdia.com.br/EconomiaEmDia/pdf/infset_feijao.pdf. Acesso em: 24 jan. 2018.

DIDONET, A. D.; VITÓRIA, T. B. Resposta do feijoeiro comum ao estresse térmico aplicado em diferentes estágios fenológicos. Pesquisa Agropecuária Tropical, Goiânia, v. 36, n. 3, p.199-204, 2006. Disponível em: http://dx.doi.org/ 10.5216/pat.v36i3.2084. Acesso em: 15 dez. 2019.

FERREIRA, A. N.; ARF, O.; CARVAlHO, M. A. C.; ARAÚJO, R. S.; SÁ, M. E. de.; BUZETTI, S. Estirpes de Rhizobium tropici na inoculação do feijoeiro. Scientia Agricola, Piracicaba, v. 57, n. 3, p.507-512, 2000. Disponível em: http://dx.doi.org/10.1590/S010390162000000300021. Acesso em: 15 dez. 2019.

FIGUEIREDO, M. A. D.; OLIVEIRA, D. P.; SOARES, B. L.; MORAIS, A. R. D.; MOREIRA, F. M. D. S.; ANDRADE, M. J. B. D. Nitrogen and molybdenum fertilization and inoculation of common bean with Rhizobium spp. in two oxisols. Acta Scientiarum. Agronomy, Maringá, v. 38, n. 1, p.85-92, 2016. Disponível em: http://dx.doi. org/10.4025/actasciagron.v38i1.26661. Acesso em: 15 dez. 2019.

FIGUEIREDO, M. A. D.; OLIVEIRA, D. P.; SOARES, B. L.; MORAIS, A. R. D.; MOREIRA, F. M. D. S.; ANDRADE, M. J. B. D. Nitrogen and molybdenum fertilization and inoculation of common bean with Rhizobium spp. in two oxisols. Acta Scientiarum. Agronomy, Maringá, v. 38 n. 1, p.85-92, 2016. Disponível em: http://dx.doi. org/10.4025/actasciagron.v38i1.26661. Acesso em: 15 dez. 2019. 
GOMES JÚNIOR, F. G.; SÁ, M. E.; VALÉRIO FILHO, W. V. Nitrogênio no feijoeiro em sistema de plantio direto sobre gramíneas. Acta Scientiarum Agronomy, Maringá, v. 30, p. 387-395, 2008. Disponível em: http://dx.doi.org/10.4025/actas ciagron.v30i3.3549. Acesso em: 12 dez. 2019.

GONTIA-MISHRA, I.; SAPRE, S.; KACHARE, S.; TIWARI, S. Molecular diversity of 1aminocyclopropane-1-carboxylate (ACC) deaminase producing PGPR from wheat (Triticum aestivum L.) rhizosphere. Plant and soil, [s. l.], v. 414, n. 1-2, p.213-227, 2017. Disponível em: https://doi.org/10.1007/s11104-016-3119-3. Acesso em: 10 dez. 2019.

HUNGRIA, M. Inoculação com Azospirillum brasilense: inovação em rendimento a baixo custo. Londrina: Embrapa Soja, 2011. Disponível em: https://www.infoteca.cnptia.embrapa.br/infoteca/handle/doc/879471. Acesso em: 10 fev 2018.

HUNGRIA, M.; ANDRADE, D. S.; COLOZZI-FILHO, A.; BALOTA, E. L. Interação entre microrganismos do solo, feijoeiro e milho em monocultura e consorcio. Pesquisa Agropecuária Brasileira, Brasília, v. 32, n. 8, p.807-818, 1997.

HUNGRIA, M.; NOGUEIRA, M. A.; ARAUJO, R. S. Co-inoculation of soybeans and common beans with rhizobia and azospirilla: strategies to improve sustainability. Biology and Fertility of Soils, $[s . \quad$ l. $], \quad$ v. $49, \quad$ n. $7, \quad$ p.791-801, 2013. Disponível em: https://doi.org/10.1007/s00374-012-0771-5. Acesso em: 5 dez. 2019.

HUNGRIA, M.; NOGUEIRA, M. A.; ARAUJO, R. S. Soybean seed co-inoculation with Bradyrhizobium spp. and Azospirillum brasilense: a new biotechnological tool to improve yield and sustainability. American Journal of Plant Sciences, [s. l.], v. 6, n. 6, p.811-817, 2015. Disponível em: http://dx. doi.org/10.4236 / ajps.2015.66087. Acesso em: 15 dez. 2019.

JESUS JÚNIOR, W. C.; VALE, F. X. R.; COELHO, R. R.; HAU, B.; ZAMBOLIM, L.; BERGER, R. D. Management of angular leaf spot in common bean (Phaseolus vulgaris L.) with molybdenum and fungicide. Agronomy Journal, Madison, v. 96, n. 3, p.665-670, 2004. Disponível em: http://dx.doi.org/10.2134/agronj2004.0665. Acesso em: 15 nov. 2019.

KANEKO, F. H.; ARF, O.; GITTI, D. C.; ARF, M. V.; FERREIRA, J. P.; BUZETTI, S. Mecanismos de abertura de sulcos, inoculação e adubação nitrogenada em feijoeiro em sistema plantio direto. Bragantia, Campinas, v. 69, n. 1, p.125-133, 2010. Disponível em: http://dx.doi.org/10.1590/S0006-87052008000 200026. Acesso em: 15 dez. 2019.

LEITE, U. T. Produção e qualidade de sementes de feijão enriquecidas com molibdênio. 2004. 97 f. Tese (Doutorado em Fitotecnia) - Universidade Federal de Viçosa, Viçosa, MG, 2004.

MELO FILHO, L. C.; CAMARGO, S. L.; LEITE, U. T.; LIMA, A. A. Adubação molíbdica em feijoeiro no cone sul de Rondônia. Revista Brasileira de Agrociência, Pelotas, v. 17, n. 2-4, p.228-233, 2011. Disponível em: http://dx.doi.org/10.18539/cast.v17i2.2053. Acesso em: 12 dez. 2019.

MOREIRA, G. B.; PEGORARO, R. F.; VIEIRA, N.; BORGES, I.; KONDO, M. K. Desempenho agronômico do feijoeiro com doses de nitrogênio em semeadura e cobertura. Revista Brasileira de Engenharia Agricola e Ambiental, [s. l.], v. 17, n. 8, 
p.818-823, 2013.

OLIVEIRA, C. A. B.; PELÁ, G. M.; PELÁ, A. Inoculação com Rhizobium tropici e adubação foliar com Molibdênio na cultura do feijão comum. Revista de Agricultura Neotropical, Cassilândia, v. 4, supl. 1, p.43-50, 2017. Disponível em: https://doi.org/10.32404/rean.v4i5. 2193. Acesso em: 5 nov. 2019.

OLIVEIRA, G.; FERREIRA, E. D. B.; DE OLIVEIRA JÚNIOR, M. J.; ESTEVES, R. Produtividade de linhagens de feijoeiro comum sob inoculação com bactérias fixadoras de $\mathrm{N}$ e adubação nitrogenada. In: SEMINÁRIO JOVENS TALENTOS, 6, 2012, Santo Antônio de Goiás. Anais [...], Santo Antônio de Goiás: Embrapa Arroz e Feijão, 2012. p. 46.

OLIVEIRA, I. P.; ARAUJO, R. S.; DUTRA, L. G. Nutrição mineral e fixação biológica de nitrogênio. In: ARAUJO, R. S.; RAVA, C. A.; STONE, L. F.; ZIMMERMANN, M. J. O. (Coord.). Cultura do feijoeiro comum no Brasil. Piracicaba: Potafos, 1996. p. 169-221.

PERES, A. R.; RODRIGUES, R. A. F.; ARF, O., PORTUGAL, J. R.; CORSINI, D. C. D. C. Co-inoculation of Rhizobium tropici and Azospirillum brasilense in common beans grown under two irrigation depths. Revista Ceres, Viçosa, v. 63, n. 2, p.198-207, 2016. Disponível em: http://dx.doi.org/10.1590/0034-737X201663020011. Acesso em: 15 dez. 2019.

PESSOA, A. C. S.; RIBEIRO, A. C.; CHAGAS, J. M.; CASSINI, S. T. A. Concentração de foliar de Mo e exportação de nutrientes pelo feijoeiro "Ouro Negro" em resposta à adubação foliar com Mo. Revista Brasileira de Ciência do Solo, Viçosa, v. 24, n. 1, p.75-84, 2000. Disponível em: http://dx. doi.org/10.1590/S0100-06832000000100010. Acesso em: 8 dez. 2019.

PORTES, T. A. Ecofisiologia. In: ARAÚJO, R. S.; RAVA, C. A.; STONE, L. F.; ZIMMERMANN, M. J. O. Cultura do feijoeiro comum no Brasil. Piracicaba: Potafós, 1996. p. 101-137.

RIBEIRO, R. A.; ORMENO-ORRILLO, E.; DALl'AGNOL, R. F.; GRAHAM, P. H.; MARTINEZ-ROMERO, E.; HUNGRIA, M. Novel Rhizobium lineages isolated from root nodules of the common bean (Phaseolus vulgaris L.) in Andean and Mesoamerican areas. Research in microbiology, $[s$. l.], v. 164, n. 7, p.740-748, 2013. Disponível em: https://doi.org/10.1016/j.resmic.2013.05.002. Acesso em: 2 dez. 2019.

ROMANINI JUNIOR, A.; ARF. O.; BINOTTI, F. F. S.; SÁ, M. E.; BUZETTI, S.; FERNANDES, F. A. Avaliação da inoculação de rizóbio e adubação nitrogenada no desenvolvimento do feijoeiro, sob sistema plantio direto. Bioscience Journal, Uberlândia, v. 23, n. 4, p.74-82, 2007.

SANTOS, M. S.; NOGUEIRA, M. A.; HUNGRIA, M. Microbial inoculants: reviewing the past, discussing the present and previewing an outstanding future for the use of beneficial bacteria in agriculture. AMB Express, [s. l.], v. 9, n. 1, p.205, 2019. Disponível em: https://doi.org/10.1186/s13568-019-0932-0. Acesso em: 01 jan. 2020.

SECRETARIA DO ESTADO DO DESENVOLVIMENTO AMBIENTAL - SEDAM. Boletim climatológico de Rondônia - 2010, Porto Velho: COGEO, 2012. 34p. Disponível em: https://docplayer.com.br/52866255-Boletim-climatologico-de-rondonia-2010.html. 
Acesso em: 20 out. 2019.

SORATTO, R. P.; CARVAlHO, M. A. C.; ARF, O. Teor de clorofila e produtividade do feijoeiro em razão da adubação nitrogenada. Pesquisa Agropecuária Brasileira, Brasília, v. 39, n. 9, p.895-901, 2004. Disponível em: http://dx.doi.org/10.1590/S0100204X2004000900009. Acesso em: 15 dez. 2019.

VALADÃO, F. C. A.; JAKELAITIS, A.; CONUS, L. A.; BORCHARTT, L.; OLIVEIRA, A. A.; VALADÃO JUNIOR, D. D. Inoculação das sementes e adubações nitrogenada e molíbdica do feijoeiro-comum, em Rolim de Moura, RO. Acta Amazonica, Manaus, v. 39, n. 4, p.741-748, 2009. Disponível em: http://dx.doi.org/10.1590/S0044-59672009000400002. Acesso em: 12 dez. 2019. 